\title{
Dexamethasone attenuation of the cortisol response to nicotine in smokers
}

\author{
O.F. Pomerleau and C.S. Pomerleau \\ Behavioral Medicine Program, Department of Psychiatry, University of Michigan School of Medicine, Ann Arbor, MI 48105, USA
}

Received October 13, 1989 / Final version November 17, 1989

\begin{abstract}
The effect of corticosteroids upon the cortisol response to nicotine from smoking was investigated in five heavy smokers. Corticosteroid activity was manipulated by administering dexamethasone, a synthetic glucocortoicoid (1 mg orally, $14 \mathrm{~h}$ before), in a doubleblind, placebo-controlled procedure. Testing took place in the middle of the day and involved the smoking of two high-nicotine $(2.87 \mathrm{mg})$ research cigarettes over a 15 -min period. The dexamethasone condition was characterized by a pronounced suppression of baseline plasma cortisol, as expected, and by a significant dampening of the cortisol response to nicotine, indicating diminished sensitivity to nicotine under conditions of enhanced corticosteroid activity.
\end{abstract}

Key words: Cortisol - Nicotine - Nicotine sensitivity - Smoking

Acute intake of nicotine by cigarette smoking increases adrenocorticotrophic hormone (ACTH) and cortisol levels in circulation in a dose-related manner (Cryer et al. 1976; Winternitz and Quillen 1977; Wilkins et al. 1982; Chiodera et al. 1984; Seyler et al. 1984; Pomerleau and Pomerleau 1988). In animals, nicotine has been shown to stimulate corticotropin releasing factor (CRF) from the hypothalamus via a nicotinic cholinergic pathway (Hillhouse et al. 1975; Weidenfeld et al. 1983), and direct application of nicotine to the hypothalamus significantly increases levels of ACTH (Marty et al. 1985) and corticosterone (Conte-Devolx et al. 1981).

Recent studies on corticosteroid modulation of sensitivity to nicotine may shed light on the functional significance of the above observations. Using inbred mice, Freund et al. (1988) demonstrated consistent strain differences in the corticosterone response to nicotine that

Offprint requests to: O.F. Pomerleau were paralleled by behavioral and physiological differences in sensitivity to nicotine. In related research, Pauly et al. (1988) found that after adrenalectomy, mice exhibited low corticosterone levels and greater sensitivity to the behavioral and physiological effects of nicotine; this effect did not appear to be mediated by rate of nicotine metabolism or differences in number or affinity of brain nicotinic receptors. Administration of exogenous corticosterone fully restored protection from nicotine's effects in all response systems measured (Y-maze rears, heart rate, startle response, and core temperature). Pauly et al. concluded that corticosteroid activity modulates sensitivity to nicotine as part of a negative feedback system that affects nicotinic receptors by a mechanism of action that is not yet understood.

It has been suggested that in humans, cortisol, a glucocorticoid, has subsumed most of the functions served by corticosterone, a mineralocorticoid with some glucocorticoid activity, in mice and rats (De Kloet et al. 1987). In the present study, corticosteroid levels were manipulated by administering dexamethasone (DEX), a synthetic glucocorticoid. The magnitude of cortisol stimulation by nicotine was used as a marker of sensitivity to nicotine. We hypothesized that DEX administration, by increasing overall corticosteroid activity, would diminish sensitivity to nicotine.

\section{Materials and methods}

Five male heavy smokers (smoking more than 20 cigarettes per day for at least 5 years), in otherwise good health and not on medications, participated in the study. Mean age was $46.4 \pm 6.4$ (SEM) years. They had smoked for $30.0 \pm 6.2$ years and reported smoking a mean of $34.0 \pm 2.9$ cigarettes per day. Mean score on the Fagerstrom Tolerance Questionnaire was $8.0 \pm 0.0$ and mean plasma cotinine level $359 \pm 40.9 \mathrm{ng} / \mathrm{ml}$, characterizing the subjects as highly nicotine-dependent. Subjects were given the Beck Depression Inventory to screen for depression (which is sometimes associated with failure to suppress cortisol levels in response to dexamethasone administration; Caroll 1978); scores ranged from 1 to 16. 
Each subject participated in two sessions. Subjects were given a tablet and instructed to take it at 2300 hours the night before a session. Tablets were either DEX (1 mg) or placebo, given in counterbalanced order using a double blind protocol. Subjects were asked to arrive at 1200 hours on the following day, having eaten a standardized breakfast but no lunch and having smoked ad libitum during the morning. They sat in an easy chair, near a console that dispensed cigarettes and signaled the start of a smoking interval. A neutral movie ("The Sound of Music") was shown on a VCR. Subjects were permitted to smoke one own-brand cigarette and then asked not to smoke until the experimental session began.

One hour later, a line was inserted in a forearm vein for sampling of plasma nicotine and cortisol levels. After waiting $20 \mathrm{~min}$ to allow cortisol levels to normalize following venipuncture, blood sampling (over a 30 -s period) began. Following 5 min of baseline measures, subjects were asked to smoke a high-nicotine research cigarette (University of Kentucky Tobacco and Health Research Institute 1 A4; yield $2.9 \mathrm{mg}$ ) over a 5 -min interval (min 5 to min 10 ); following a $5 \mathrm{~min}$ rest $(\min 10$ to $\min 15)$, they were asked to smoke a second cigarette ( $\min 15$ to $\min 20$ ). Blood samples were withdrawn at min $0,5,10,20,30,40$ and 55 .

Samples were analyzed for nicotine and cortisol in plasma using RIA (see Seyler et al. 1984). Statistical analyses involving repeated measures ANOVA and ANCOVA were carried out using BMDP2V. Since uni-directional hypotheses were specified, all statistical probabilities reported are one-tailed.

\section{Results}

All subjects showed profound baseline depressions of cortisol in the DEX condition (Martin and Reichlin 1987), confirming compliance with instructions to selfadminister the tablets.

Time course for plasma cortisol over the two conditions is shown in Fig. 1. A 2 (DEX versus placebo) $\times 7$ (time points) ANOVA was conducted. A significant time effect $[F(6,24=3.88, P=0.0038]$, with a significant linear trend $[F(1,4)=4.79, P=0.0470]$, was revealed, showing the effect of nicotine upon cortisol; a highly significant DEX effect $[F(1,4)=60.09, P=0.0008]$ was also seen, as expected. A significant interaction effect $[F(6,24)=$ $3.38, P=0.0084]$, apparently attributable to the attenuating effects of DEX upon the cortisol response, was detected as well.

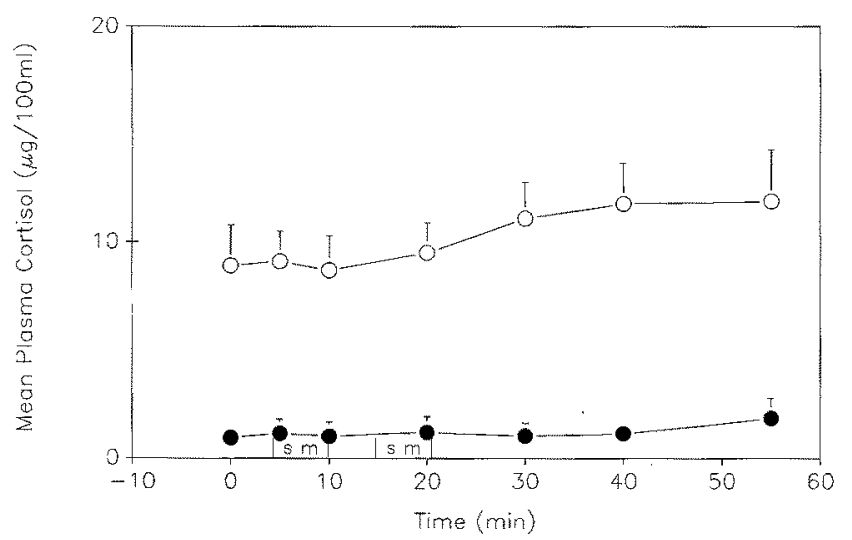

Fig. 1. Mean plasma cortisol levels before and after smoking two high-nicotine $(2.9 \mathrm{mg})$ cigarettes, approximately $14 \mathrm{~h}$ after administration of placebo or dexamethasone $(1 \mathrm{mg}) ;$ mean $\pm \mathrm{SEM} ; N=5$. o-O Placebo; - dexamethasone
Table 1. Baseline (minute 0), peak (maximal value), and change in cortisol levels $(\mu \mathrm{g} / 100 \mathrm{ml})$ for placebo and dexamethosone conditions

\begin{tabular}{|c|c|c|c|c|c|c|}
\hline \multirow{2}{*}{$\begin{array}{l}\text { Sub- } \\
\text { ject }\end{array}$} & \multicolumn{3}{|l|}{ Placebo } & \multicolumn{3}{|l|}{ DEX } \\
\hline & Baseline & Peak & Change & Baseline & Peak & Change \\
\hline 1 & 6.5 & 9.7 & 3.2 & 0.0 & 0.0 & 0.0 \\
\hline 2 & 16.2 & 19.9 & 3.7 & 2.0 & 4.0 & 2.0 \\
\hline 3 & 7.3 & 7.4 & 0.1 & 0.6 & 0.7 & 0.1 \\
\hline 4 & 7.9 & 14.7 & 6.8 & 0.9 & 4.9 & 4.0 \\
\hline 5 & 6.5 & 9.9 & 3.4 & 1.3 & 1.1 & -0.2 \\
\hline $\bar{X}$ & 8.9 & 12.3 & 3.4 & 1.0 & 2.1 & 1.2 \\
\hline SEM & \pm 1.8 & \pm 2.2 & \pm 1.1 & \pm 0.3 & \pm 1.0 & \pm 0.8 \\
\hline
\end{tabular}

In order to focus more clearly on the cortisol response to nicotine administration, peak post-smoking values were calculated as shown in Table 1; as can be seen, four of the five subjects exhibited greater stimulation of cortisol by nicotine in the placebo condition than the DEX condition; the fifth showed the same increase for both conditions. A one-way ANOVA with four levels of time (min 0/placebo, min 0/DEX, peak/placebo, and peak/DEX) was conducted; using the Bonferroni statistic, it was established that peak values were significantly higher than baseline $(\min 0)$ values for the placebo condition $(P<0.05)$ but not for the DEX condition. In order to take into account individual differences in nicotine intake in the two conditions, cortisol change per unit nicotine increment was also computed, and again significantly higher changes were found for the placebo condition than for the DEX condition $(t=2.65$, $P=0.0286$ ). Subjects showed a tendency towards a characteristic cortisol response to nicotine, as indicated by a Pearson correlation coefficient of $0.796(P=0.0537)$ between cortisol changes on the placebo day and on the DEX day.

In the DEX condition, the mean plasma nicotine presmoking level was $14.4 \pm 2.0 \mathrm{ng} / \mathrm{ml}$ and the peak postsmoking level was $34.1 \pm 4.0 \mathrm{ng} / \mathrm{ml}$; in the placebo condition, the pre-smoking level was $14.4 \pm 3.0 \mathrm{ng} / \mathrm{ml}$ and the peak post-smoking level was $27.9 \pm 2.1 \mathrm{ng} / \mathrm{ml}$. A repeated measures ANCOVA was conducted on peak values, using min 0 values as a covariate, revealing a trend towards a significant difference $[F(1,3)=3.19, P=0.0859]$.

\section{Discussion}

There was significant dampening of the cortisol response to nicotine following DEX administration, despite somewhat higher nicotine intake in that session, indicating diminished sensitivity to nicotine as a result of synthetic corticosteroid administration. The magnitude of the stimulation of cortisol by nicotine in the placebo condition was nearly identical to that found under similar conditions in a recent study by Chiodera et al. (1984). Since ACTH levels were not measured directly, it is not clear to what extent this effect was mediated through 
steroid inhibitory control mechanisms at the level of the hypophysis (Cam et al. 1979) or through possible action of the synthetic corticosteroid on nicotinic receptors at the level of the adrenal cortex (Rubin and Warner 1975). There was also a trend towards a significant correlation between cortisol boost for the DEX and placebo conditions, suggesting characteristic individual differences in response to nicotine.

These findings confirm and extend to the human level the observation of corticosteroid modulation of behavioral and physiological sensitivity to nicotine in animals (Freund et al. 1988; Pauly et al. 1988). The findings will now need to be replicated in a larger sample of smokers (and non-smokers), using a variety of synthetic corticosteroids and additional physiological and behavioral measures of sensitivity. The significance of the research is not only that it suggests mechanisms for explaining acute tolerance resulting from nicotine administration but also that it predicts changes in sensitivity to nicotine in other conditions that modify corticosteroid levels, such as physical and psychological stress (Brenner et al. 1986; Pomerleau and Pomerleau 1989).

Acknowledgements. Partial support for this research was provided by National Cancer Institute Grant CA/DA 42730. The authors thank Allan C. Collins, PhD, for his helpful comments and encouragement.

\section{References}

Brenner T, Mizrachi R, Bodoff M, Weidenfeld J (1986) Evidence that nicotinic-acetylcholine receptors are involved in the modulation of basal and stress-induced adrenocortical responses. Exp Neurol 94:735-743

Cam GR, Bassett JR, Cairncross KD (1979) The action of nicotine on the pituitary-adrenal cortical axis. Arch Int Pharmacodyn 237:49-66

Carroll B (1978) Neuroendocrine function in psychiatric disorders. In: Lipton MA, DiMascio A, Killam KF (eds) Psychopharmacology: a generation of progress. Raven Press, New York, pp 487-495

Chiodera L, Camellini G, Rossi G, Maffei ML, Volpi R, Coiro $V$ (1984) Effects of clonidine on ACTH and cortisol release induced by cigarette smoking in man. Horm Metab Res 16:501502

Conte-Devolx B, Oliver C, Giraud P, Guillioz P, Castanas E, Lissistzky JC, Boudouresque F, Millet Y (1981) Effect of nico- tine on in vivo secretion of melanocorticotropic hormones in the rat. Life Sci 28:1067-1073

Cryer PE, Haymond MW, Santiago JV, Shah SD (1976) Norepinephrine and epinephrine release and adrenergic mediation of smoking associated hemodynamic and metabolic events. $\mathrm{N}$ Engl J Med 295:573-577

De Kloet ER, Ratka A, Reul JM, Sutanto W, Van Eekelen IAM (1987) Corticosteroid receptor types in brain: regulation and putative function. In: Ganong WF, Dallman MF, Roberts JL (eds) The hypothalamic-pituitary-adrenal axis revisited. New York Academy of Sciences, New York, pp 351-361

Freund RK, Martin BJ, Jungschaffer DA, Ullman EA, Collins $\mathrm{AC}$ (1988) Genetic differences in plasma corticosterone levels in response to nicotine injection. Pharmacol Biochem Behav 30: $1059-1064$

Hillhouse EW, Burden I, Jones MT (1975) The effect of various putative neurotransmitters on the secretion of corticotropinreleasing hormones from the rat hypothalamus in vitro - a model of the neurotransmitters involved. J Endocrinol $69: 1-10$

Martin JB, Reichlin S (1987) Clinical neuroendocrinology, 2nd edn. Davis, Philadelphia, pp 159-176

Marty M, Erwin V, Cornell K, Zgombick J (1985) Effects of nicotine on beta-endorphin, alpha-MSH, and ACTH secretion by isolated perfused mouse brain and pituitary glands, in vitro. Pharmacol Biochem Behav 22:317-325

Pauly JR, Ullman EA, Collins AC (1988) Adrenocortical hormone regulation of nicotine sensitivity in mice. Physiol Behav 44:109116

Pomerleau OF, Pomerleau CS (1988) Neuroendocrine response to nicotine on cigarette smokers. In: Rand MJ, Thurau K (eds) International symposium on nicotine. ICSU Press, Florida, pp 321-335

Pomerleau OF, Pomerleau CS (1989) Biobehavioral studies in humans: anxiety, stress, and smoking. In: Bock G, Marsh J (eds) The biology of nicotine dependence [CIBA Foundation Symposium 152]. Wiley, Chichester, UK (in press)

Rubin RP, Warner W (1975) Nicotine-induced stimulation of steroidogenesis in adrenocortical cells of the cat. Br J Pharmacol $53: 357-362$

Seyler LE, Fertig JB, Pomerleau OF, Hunt D, Parker K (1984) The effects of smoking on ACTH and cortisol secretion. Life Sci $34: 57-65$

Weidenfeld J, Siegel R, Conforti N, Mizrachi R, Brenner T (1983) Effect of intracerebroventricular injections of nicotinic acetylcholine receptor antibodies on $\mathrm{ACTH}$, corticosterone and prolacticin secretion in the male rat. Brain Res 265:152-156

Wilkins IN, Carson HE, van Vunakis H, Hill MA, Gritz E, Jarvik ME (1982) Nicotine from cigarette smoking increases circulating levels of cortisol, growth hormone, and prolactin in male chronic smokers. Psychopharmacology 78:305-308

Winternitz WW, Quillen D (1977) Acute hormonal responses to cigarette smoking. J Clin Pharmacol 17:389-397 